\title{
Transparency in evaluation through the use of rubrics in University subjects
}

\author{
Leticia C. Velasco Martínez* \\ leticiav@uma.es \\ Juan Carlos Tójar Hurtado \\ jctojar@uma.es




\section{Introduction}

- Scoring Rubrics:

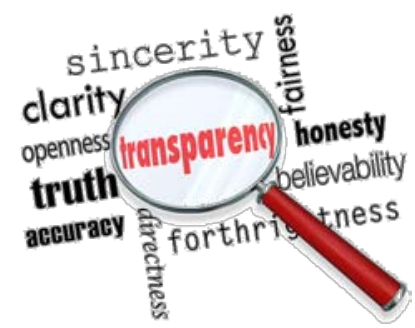

- Evaluation more systematized / less arbitrariness and subjectivity

- Teachers:

- To make their vision, purposes and expectations explicit regarding evaluation.

- To show their students (transparent and precise way):

- The learning objectives

- The evaluation criteria

- The weight that the activities will have in the final grade.

- Students assume:

- A more prominent role in their learning processes

- A more aware of their potentialities and limitations (level of competency)

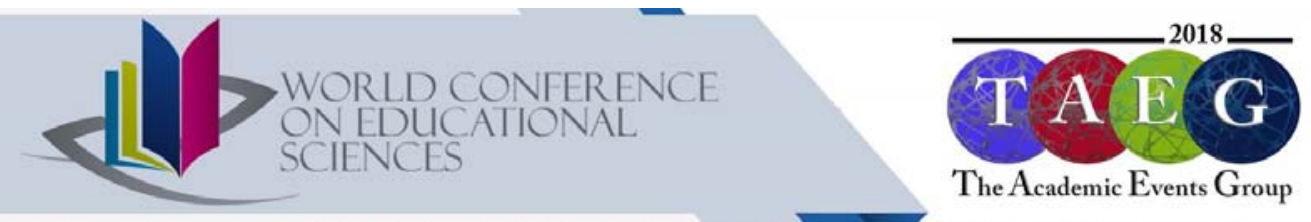




\title{
Introduction
}

The formative value of rubrics also becomes clear when they are defined, agreed and socialized with the class-group

\author{
... but
}

Are rubrics regarded as an evaluation tool that brings more TRANSPARENCY, DIALOGUE and CO-RESPONSIBILITY to evaluation processes?

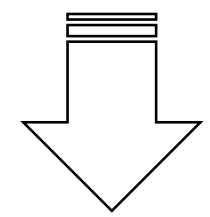

Institutions, teachers and researchers don't have a shared vision of their meaning, applications and impact on learning development.

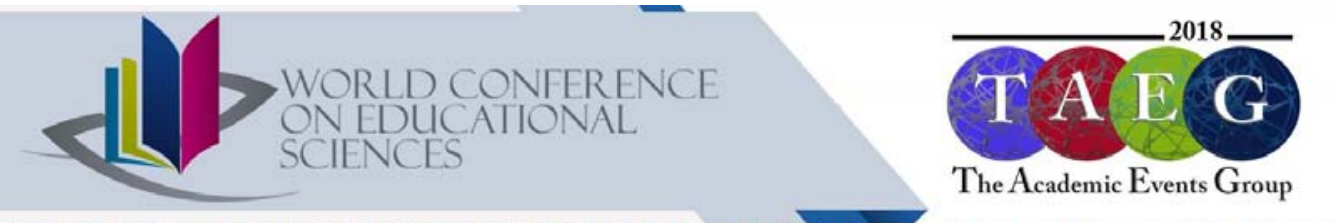




\section{Purpose of study}

Conceptions and opinions of professional of education about:

Level of transparency in evaluation methods, strategies and criteria used by university teaching staff.

$\square$ Key factors and elements involved in a more meaningful and participatory evaluation

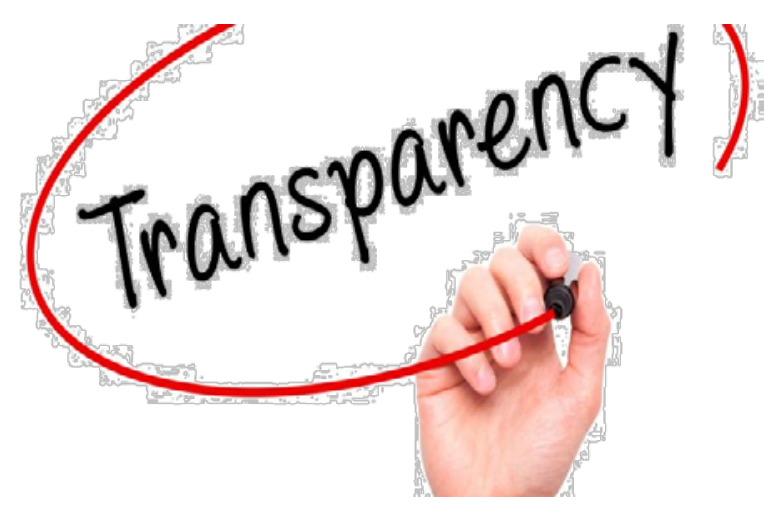




\section{Methods}

- Sample no probabilistic (incidental): 22 educators, researchers and heads of Mexican university.

- Qualitative approach $\rightarrow$ Application of in-depth interviews.

- Model mixed of category for the collection of information:

1) Inductive categorization (analysis of the content of the interviews)

2) Deductive categorization (analysis of theoretical models from the review of the scientific literature)

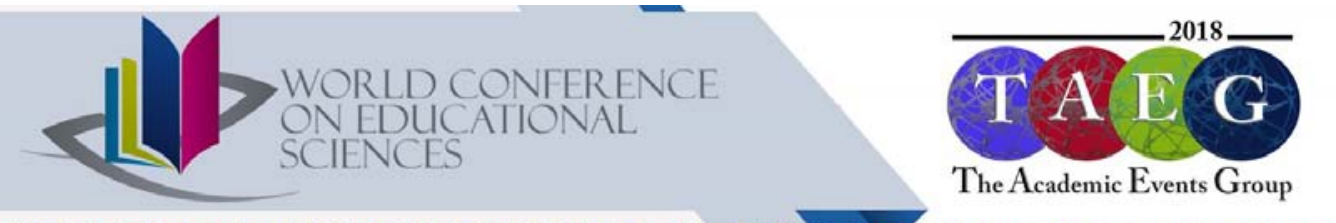




\section{Methods}

The analysis content of the interviews were carried out:

1) Reduction of interview texts

2) Transformation of date through the organization and associations between fragments of the text.

3) Extraction and verification of conclusions to build models and theories to represent the studied phenomenon.

4) Elaboration of matrices and graphs to visualize and interpret of information. 


\section{Results}

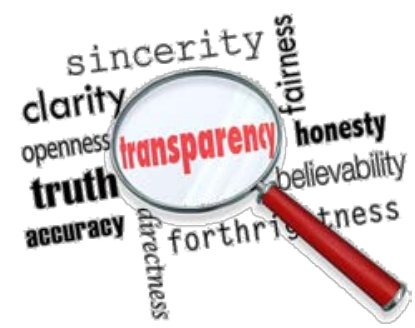

22 interviews

21,846 Units of análisis

\section{2,041 verbatim citations}

75 categories

\section{4 subcategories}

\section{Two categories}

1) Transparency in the technical design of the rubric (TTD)

2) Transparency in the pedagogical design of the rubric (TPD)

\footnotetext{
Velasco-Martínez \& Tójar-Hurtado (2019).

Transparency in evaluation through the use of rubrics in University subjects
} 


\section{Results}

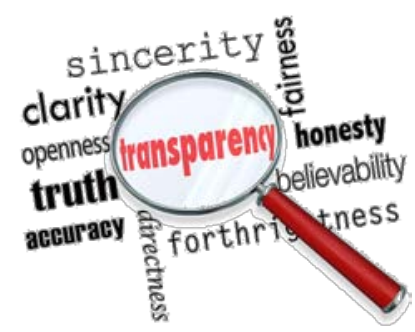

Tabla 1. Categories and verbatim quotes of technical design of the rubric.

\begin{tabular}{|c|c|c|}
\hline Category & \multicolumn{1}{c|}{ Verbatim quotes } \\
\hline $\begin{array}{c}\text { The rubric shows } \\
\text { students where they } \\
\text { are and how far they } \\
\text { still have to go. } \\
\text { (PL) }\end{array}$ & $\begin{array}{l}\text { "...it's interesting for students to understand what } \\
\text { stayed behind, and that 'where do I stay behind' is the } \\
\text { exact question they need.” (P21:58, 87:87) }\end{array}$ \\
\hline
\end{tabular}

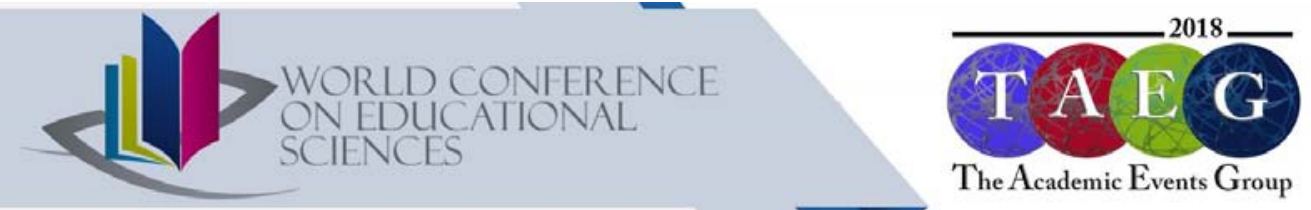

Velasco-Martínez \& Tójar-Hurtado (2019).

Transparency in evaluation through the use of rubrics in University subjects 


\section{Results}

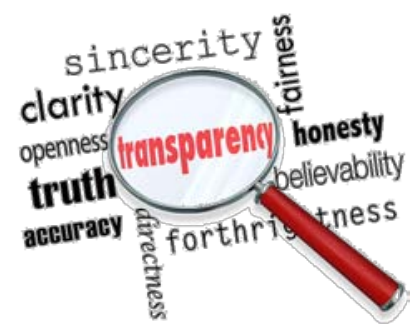

Tabla 1. Categories and verbatim quotes of pedagogical design of the rubric.

\begin{tabular}{|c|l|}
\hline Category & \multicolumn{1}{c|}{ Verbatim quotes } \\
\hline $\begin{array}{c}\text { A rubric generates } \\
\text { commitment and } \\
\text { responsibility in the } \\
\text { improvement of } \\
\text { learning. } \\
(C R)\end{array}$ & $\begin{array}{l}\text { “. it gives students the possibility to observe } \\
\text { and to appropriate their own process of learning, then } \\
\text { they are no longer at the mercy of the teacher". } \\
(\mathrm{P} 21: 86,139: 139) .\end{array}$ \\
\hline
\end{tabular}

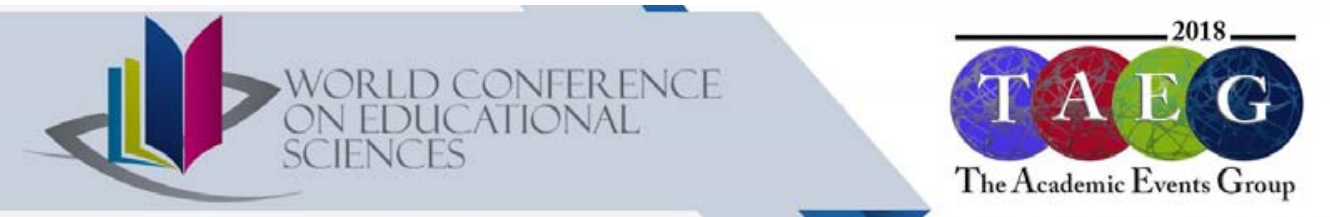




\section{Conclusions}

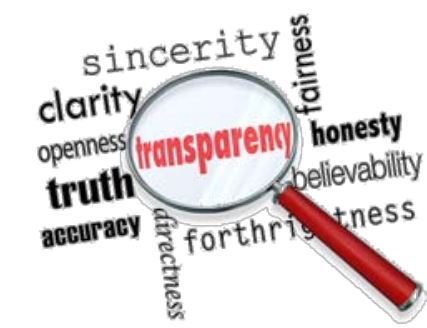

- The categorization process shows the benefits of rubrics as an evaluation instrument that provides transparency to students' learning process.

- Rubrics improve evaluation transparency when the criteria, components and weights of the evaluation and of the grade are public, consensual, and shared with the students

- Finally, it is essential to design and apply rubrics that provide assessment transparency in order to promote students' interest, participation and understanding of their own learning and assessment process 


\title{
Transparency in evaluation through the use of rubrics in University subjects
}

\author{
Leticia C. Velasco Martínez* \\ leticiav@uma.es \\ Juan Carlos Tójar Hurtado \\ jctojar@uma.es

